\title{
Probing the energy efficiency of microwave heating and continuous-flow conventional heating as tools for organic chemistry
}

\author{
William G. Devine and Nicholas E. Leadbeater* \\ Department of Chemistry, University of Connecticut, 55 North Eagleville Road, \\ Storrs, CT 06269-3060 USA \\ E-mail: nicholas.leadbeater@uconn.edu
}

\section{Dedicated to William F. Bailey on the occasion of his $65^{\text {th }}$ birthday; a great colleague, source of wisdom and fellow conspirator}

\begin{abstract}
The energy efficiency of using microwave heating has been compared with batch and continuous-flow conventional heating for three reactions. As expected, as the scale is increased so the energy efficiency improves. In addition, the energy consumption is similar for both sealed and open vessel microwave processing. When using a conventionally heated continuous-flow approach, while the energy efficiency is significantly lower at small scales, as the scale in increased so the efficiency improves significantly. To probe the differences between conventional and microwave heating further, calculations based on heating water from room temperature to its boiling point in open-vessel batch mode are reported. While the conversion of electrical energy into heat by a heating mantle is significantly more efficient than conversion of electrical energy into microwave energy by the magnetron of a microwave unit, the fact that water can be heated so much faster using microwave irradiation as opposed to conventional heating means that, overall, the two methods are comparable in their energy consumption.
\end{abstract}

Keywords: Microwave heating, flow chemistry, energy, Hantzsch synthesis, Suzuki coupling, alkylation

\section{Introduction}

Microwave heating is a valuable tool for synthetic chemists because it is possible to enhance the rate of reactions and, in many cases, improve product yields. ${ }^{1}$ A range of scientific microwave apparatus is commercially available. It is designed with ease of use and safety in mind, making microwave heating a very accessible technology. The majority of the publications in the area of microwave-promoted organic synthesis relate to small scale chemistry $(0.5-10 \mathrm{mmol})$. An area of increasing research interest now is the scale-up of microwave-promoted chemistries. ${ }^{2,3}$ 
Alongside this comes the issue of energy efficiency. In their report on comparing the energy efficiency of various heating methods, including microwave heating, Clark and co-workers report a significant reduction in energy demand on switching from oil bath to microwave for a Suzuki reaction. ${ }^{4}$

In 2008, Razzaq and Kappe reported a study of the energy efficiency of four reactions under a number of microwave conditions including the use of sealed vessels and open glassware. They conclude that the efficiency of microwave heating is dependent on the conditions used but is only superior to conventional heating when using a superheated solvent in a sealed vessel. ${ }^{5}$ The relative efficiencies of microwave and conventional methods for heating solvents have also been reported. ${ }^{6}$ Not surprisingly, the efficiency of microwave heating was highly dependent on the dielectric constant of the solvent. In 2009, there have been a number of somewhat contradictory reports. Hoogenboom and co-workers have probed the energy efficiency of microwave heating for a number of solvents on a small scale and then deionized water on scales from 5-400 mL. ${ }^{7}$ They report "maximum average heating efficiencies of $10 \%$ for small-scale vessels $(5 \mathrm{~mL}), 20 \%$ for medium-scale $(50 \mathrm{~mL})$, and $30 \%$ for large-scale microwave heating $(400 \mathrm{~mL})$ ". Moseley and Woodman have reported on the energy efficiency of microwave heating at 1-3 L scale. ${ }^{8}$ Four scientific microwave units were compared to each other and against a conventionally-heated jacketed reaction vessel for four organic reactions under identical conditions. The conclusions were that microwave heating can be more energy-efficient than conventional heating but that it is highly dependent on the microwave unit used and the scale at which the reaction is performed. Komorowska and co-workers have studied the influence of microwave irradiation on a polyesterification reaction. ${ }^{9}$ They suggest that energy loss in the magnetron and the cavity make microwave heating less energy efficient and hence less economical than conventional heating. A similar assertion is made by Dressen and co-workers in a 2010 report. ${ }^{10}$ They state that microwave heating loses at least two times more energy in its fore-track and that the energy bill is at least a factor of eight higher as compared to steam heating for industrial applications.

Another tool of current topical interest is conventionally heated continuous-flow processing on a micro- and meso-scale. It is possible to perform reactions effectively both at high and low temperatures by means of heating or cooling blocks around which the reactants pass in tubing of various diameters. The technology has particular benefit when performing reactions that involve use of potentially hazardous, or unstable reactants. Only a small quantity of material is directly in the reaction zone at any one time. In addition, there is literature precedent for translation of synthetic organic protocols from microwave to flow chemistry. ${ }^{11}$ We wanted to probe the energy efficiency of microwave heating, conventionally heated batch and conventionally heated continuous-flow approaches. To achieve this, we selected three reactions and performed them over a range of different scales. In an allied project we also probed the efficiency of conversion of electrical energy into heat for both conventional and microwave methods when working on the liter scale. We present our results here. 


\section{Results and Discussion}

As test reactions we decided to focus attention on the Hantzsch synthesis of a 1,4dihydropyridine, the Suzuki coupling of 4-bromoanisole with phenylboronic acid and the preparation of $\mathrm{N}$-phenylpiperidine from aniline and 1,5-dibromopentane. Our motivation for choosing these comes, in the case of the first two, from our previous experience developing methodologies and, in the case of the third, reports in the literature of both small ${ }^{12}$ and larger $^{13}$ scale protocols. To measure energy efficiency we used the same methods as reported previously. ${ }^{4,5}$ We placed a watt-meter in series between the power supply and either the microwave unit or the flow apparatus. We measured the watts consumed during the total heating time and, to normalize the data across the different scales of reactions performed we determined energy consumption on the basis of millimoles of product formed. This was achieved by factoring in the scale of the reaction, the product yield obtained and the energy consumed in watt-hours per mmol of product formed (Wh.mmol ${ }^{-1}$ ).

\section{Hantzsch 1,4-dihydropyridine synthesis}

Microwave heating has been used extensively for performing this multicomponent reaction which involves condensation of an aldehyde with a $\beta$-dicarbonyl compound and ammonia. ${ }^{14}$ In our laboratory we have recently developed a procedure, first on the small scale in a monomode microwave and then scaled to 1 mole in a multimode unit. ${ }^{15}$ For our energy efficiency studies we used these optimized conditions, performing the reaction using benzaldehyde (1 eq.), ethylacetoacetate (3.4 eq.) and $28 \%$ aqueous ammonium hydroxide (10 eq.) as reagents and a 1 : 1 mix of ethanol and water (v:v) as solvent. Using a monomode microwave unit, we ran the reaction on the $1 \mathrm{mmol}$ scale in a $10 \mathrm{~mL}$ capacity sealed vessel and then on the 5 and $10 \mathrm{mmol}$ scales in an $80 \mathrm{~mL}$ capacity sealed vessel, the concentration being kept constant. Each reaction was run for a total time of $15 \mathrm{~min}$ using an initial microwave power of $50 \mathrm{~W}$, heating to $110{ }^{\circ} \mathrm{C}$. The results are shown in Table 1 . The process becomes significantly more energy efficient with increasing scale; the $1 \mathrm{mmol}$ reaction requiring $54.2 \mathrm{Wh}_{\mathrm{mmol}}{ }^{-1}$ (Table 1 , entry 1) while that on

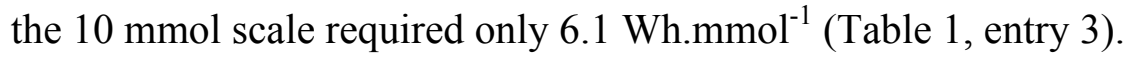

We moved next to an open-vessel arrangement, still using the monomode microwave unit. We performed the reaction first on the $5 \mathrm{mmol}$ scale and found that the energy efficiency was comparable to the sealed-vessel analog; $19.8 \mathrm{Wh}_{\mathrm{Wmol}}^{-1}$ vs. $20.4 \mathrm{Wh} \cdot \mathrm{mol}^{-1}$ (Table 1, entries 2 and 4 respectively). When run on the $10 \mathrm{mmol}$ scale, the product yield obtained was significantly lower than either the sealed vessel analog or the $5 \mathrm{mmol}$ open-vessel trial. On the $10 \mathrm{mmol} \mathrm{scale}$, the reaction volume is close to capacity for the flask used and it took some considerable time to reach reflux using only $50 \mathrm{~W}$ initial microwave power. As a result, the energy efficiency of the reaction measured in Wh per mmol of product was substantially larger for the open vessel run compared to the analogous sealed vessel experiment; 6.1 Wh.mmol ${ }^{-1}$ vs. 10.2 Wh.mmol ${ }^{-1}$ (Table 1 , entries 3 and 5 respectively). 
Table 1. Probing the energy efficiency of the microwave-promoted Hantzsch 1,4dihydropyridine synthesis

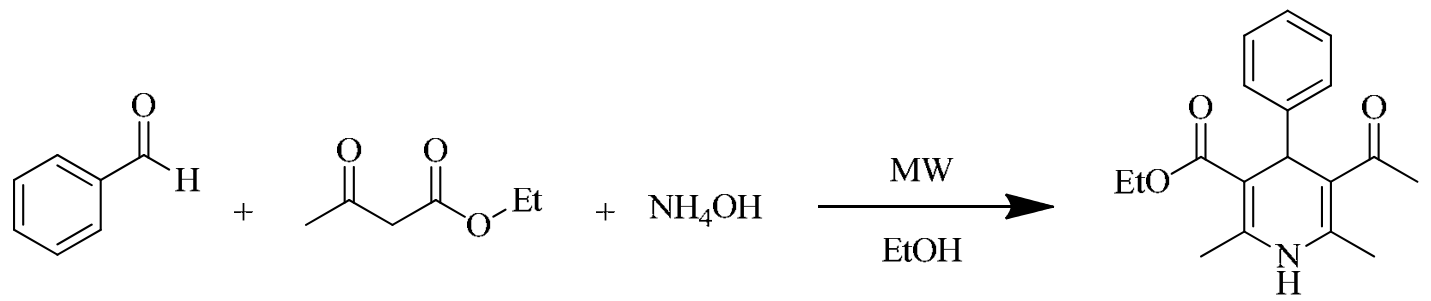

\begin{tabular}{|c|c|c|c|c|c|}
\hline Entry & Conditions & $\begin{array}{l}\text { Reaction time } \\
(\min )^{\mathrm{a}}\end{array}$ & $\begin{array}{c}\text { Conversion } \\
(\%)\end{array}$ & $\begin{array}{l}\text { energy used } \\
(\mathrm{Wh})^{\mathrm{b}}\end{array}$ & $\mathrm{Wh}_{\mathrm{mmol}}{ }^{-1}$ \\
\hline 1 & 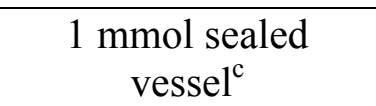 & 15 & 64 & 34.7 & 54.2 \\
\hline 2 & $\begin{array}{c}5 \mathrm{mmol} \text { sealed } \\
\text { vessel }^{\mathrm{c}}\end{array}$ & 15 & 50 & 49.5 & 19.8 \\
\hline 3 & $\begin{array}{c}10 \mathrm{mmol} \text { sealed } \\
\text { vessel }^{\mathrm{c}}\end{array}$ & 15 & 71 & 43.3 & 6.1 \\
\hline 4 & $5 \mathrm{mmol}^{\text {open vessel }}{ }^{\mathrm{c}}$ & 15 & 49 & 50.9 & 20.4 \\
\hline 5 & $\begin{array}{l}10 \text { mmol open }_{\text {vessel }^{\mathrm{c}}}\end{array}$ & 15 & 43 & 43.4 & 10.2 \\
\hline 6 & $\begin{array}{l}100 \text { mmol open }_{\text {vessel }^{\mathrm{d}}}\end{array}$ & 15 & 65 & 200 & 3.1 \\
\hline 7 & 1 mol open vessel ${ }^{d}$ & 30 & 54 & 620 & 1.1 \\
\hline 8 & $\begin{array}{c}200 \mathrm{mmol} \mathrm{sealed}^{\mathrm{dessel}} \\
\text { vesse }^{\mathrm{d}}\end{array}$ & 20 & 42 & 190 & 2.3 \\
\hline 9 & $100 \mathrm{mmol}^{\mathrm{flow}}{ }^{\mathrm{e}}$ & 15 & 53 & 466 & 8.8 \\
\hline
\end{tabular}

atotal reaction time.

benergy consumption as measured by the power meter for the entire reaction time.

${ }^{\mathrm{c}}$ performed in a monomode microwave unit.

dperformed in a multimode microwave unit.

e performed using conventional heating in continuous-flow mode.

To perform the reaction on a larger scale using open-vessel conditions we turned to a multimode microwave unit. Running the reaction at the $100 \mathrm{mmol}$ scale required $3.1 \mathrm{Wh}^{\mathrm{mmol}}{ }^{-1}$ (Table 1, entry 6). When scaling up further to 1 mole we knew from previous experience that the reaction time needed to be lengthened and thus we performed our experiment using a total time of $30 \mathrm{~min}$ as opposed to the $15 \mathrm{~min}$ used for the smaller-scale runs. Despite this, the reaction 
required only 1.1 Wh.mmol $^{-1}$ (Table 1 , entry 7 ). We finally turned back to sealed-vessel processing and performed the reaction on the $200 \mathrm{mmol}$ scale, running the reaction for $20 \mathrm{~min}$. Requiring 2.3 Wh.mmol ${ }^{-1}$ (Table 1, entry 8), this is in line with the expected value for open vessel processing at the same scale.

We next performed the reaction using conventional heating in continuous-flow mode. We used a flow reactor designed for synthetic chemistry (Uniqsis FlowSyn). ${ }^{16}$ The equipment comprises an electrically heated aluminium block, around which a pre-wound cartridge of narrow-gauge $(1.00 \mathrm{~mm} \times 1.57 \mathrm{~mm}$ o.d.) PTFE tubing was placed, the total volume in the heated zone being $14 \mathrm{~mL}$. Reagents passed through the heated zone driven by a variable $(0-10 \mathrm{~mL} /$ min) high-pressure pump. Once out of the heated zone, the product mixture was mixed with a stream of ethyl acetate via a T-piece, this being used to avoid precipitation of the product in the PTFE tubing. The mixture was then passed through a back-pressure regulator, into a heat exchanger and then to a $100 \mathrm{~mL}$ capacity collection vessel. The block was first heated from room temperature to $110{ }^{\circ} \mathrm{C}$, passing ethanol through the coil reactor, from bottom to top, at a rate of 1 $\mathrm{mL} / \mathrm{min}$, this taking $54 \mathrm{Wh}$ of energy. Once at temperature, the flow was then changed from solvent to reaction mixture by means of a switch on the control unit. A $100 \mathrm{mmol}$ batch of reaction mixture was then passed through the coil reactor at a rate of $1 \mathrm{~mL} / \mathrm{min}$. As the mixture neared the end of the coil reactor, an empty, clean collection vessel was put in place. After all the reaction mixture had entered the coil reactor, the flow was changed back to solvent and ethanol flowed through the reactor at a rate of $1 \mathrm{~mL} / \mathrm{min}$ to push the remaining reaction mixture through and out into the collection vessel. As soon as this was achieved, the flow was stopped and the total energy used was noted as $466 \mathrm{Wh}$. Factoring in the product yield, the continuous-flow process was found to require $8.8 \mathrm{Wh}_{\mathrm{mmol}}{ }^{-1}$ (Table 1, entry 9). This makes it less efficient than the microwave analog. This is due, at least in part, to the significantly longer total time required to process the reaction mixture when using the flow approach.

\section{Suzuki coupling reaction}

We turned our attention next to the Suzuki coupling reaction between 4-bromoanisole and phenylboronic acid (Table 2). Our interest in this reaction was two-fold. Firstly, we have studied the reaction extensively before both on small and larger scales, developing a range of methodologies using ultra-low levels of palladium catalysts and either water or a $1: 1$ mix of ethanol and water (v:v) as solvent. ${ }^{15,17,18}$ Secondly, this same reaction was studied by Razzaq and Kappe in their energy efficiency studies using different microwave units ${ }^{5}$ so we wanted to be able to compare our results with theirs.

Again we started our study by working on the $1 \mathrm{mmol}$ scale in a sealed tube, performing the reaction by heating to the target temperature of $150{ }^{\circ} \mathrm{C}$ using an initial microwave power of 50 $\mathrm{W}$. We ran the reaction for a total time of $3 \mathrm{~min}$ and determined the energy consumption to be 9.8 Wh.mmol ${ }^{-1}$ (Table 2, entry 1). When performing a reaction under a time / temperature protocol, the microwave unit uses the set initial power to ramp the reaction mixture to the desired temperature as rapidly as possible. Once at temperature, the microwave power usually drops 
significantly and fluctuates to hold the reaction mixture isothermally until the total time elapses. During the time, little power is used and, as a consequence, this phase is much less energy intensive than the period ramping to temperature. We wanted to see if changing the initial microwave power used would have an impact on the energy efficiency of the overall reaction. By using a higher microwave power we would be consuming more energy to reach the target temperature but would get there faster. We performed the reaction for a total time of 3 min using initial microwave powers of $200 \mathrm{~W}$ and $300 \mathrm{~W}$ to ramp to $150{ }^{\circ} \mathrm{C}$ and determined energy consumptions of $10.8 \mathrm{Wh} . \mathrm{mmol}^{-1}$ and $10.5 \mathrm{Wh}_{\mathrm{mmol}}{ }^{-1}$ respectively (Table 2, entries 2 and 3). This shows that the energy efficiency of the reaction is not significantly affected by changing the initial microwave power used.

We moved next to the $10 \mathrm{mmol}$ scale, performing the reaction in both sealed and open vessels. From our previous work we knew that as we increased the scale so we needed to lengthen the total reaction time from $3 \mathrm{~min}$ to $10 \mathrm{~min}$ in order to obtain good yields of the biaryl product. We determined the energy consumption of the sealed-vessel procedure to be 4.8 Wh.mmol ${ }^{-1}$ (Table 2, entry 4) while that for the open vessel analog was $4.4 \mathrm{Wh} \cdot \mathrm{mmol}^{-1}$ (Table 2, entry 5), again showing parity between the two. We scaled up the open vessel protocol to 20 $\mathrm{mmol}$, the largest possible in the monomode microwave unit, and determined an energy consumption of $2.0 \mathrm{Wh} . \mathrm{mmol}^{-1}$ (Table 2, entry 6). Moving to larger scales required changing to the multimode microwave unit. Increasing the total reaction time to $20 \mathrm{~min}$ we performed the coupling on the $100 \mathrm{mmol}$ and $200 \mathrm{mmol}$ scales, determining energy consumptions to be 2.6 Wh.mmol ${ }^{-1}$ and 1.7 Wh.mmol ${ }^{-1}$ respectively (Table 2, entries 7 and 8). These data show a similar trend to those from the 1,4-dihydropyridine synthesis; namely the greater the scale, the more energy efficient the reaction. Performing the reaction in a sealed vessel at the $100 \mathrm{mmol}$ scale in the multimode microwave required $2.0 \mathrm{Wh} \cdot \mathrm{mmol}^{-1}$ (Table 2, entry 9) which is close to that for the open vessel analog, confirming that there is little difference in energy consumed between the two processing methods.

Comparing our energy consumption data to those from Razzaq and Kappe, ${ }^{5}$ we find that while on a larger scale our results are directly comparable, when considering the small sealed vessel experiments our figures differ substantially. This could be attributed to the different instruments used in our respective studies, a conclusion that is supported by the data obtained by Razzaq and Kappe for another reaction where they had used two different monomode microwave units and found a substantial difference in energy consumption between them when using identical reaction conditions.

Turning next to conventional heating in continuous-flow mode, we wanted to perform the reaction on the 50 and $100 \mathrm{mmol}$ scales. Although flow chemistry has a number of advantages, a significant issue arises when performing chemistry involving heterogeneous reaction mixtures. This is the case with the Suzuki coupling protocol here. A significant amount of base is used in the reaction, much of which is not soluble at room temperature in the aqueous ethanol solvent. Therefore, passing this through the flow reactor was not going to be feasible. We turned our attention to an alternative methodology that we have developed for the coupling that involved the 
use of sodium hydroxide as base and ethanol / water as the solvent. In this case all the reagents are soluble making it possible to pump through the flow reactor. The biaryl product, however, is not particularly soluble at room temperature and so there was the potential for clogging either the back-pressure regulator or the exit tube. As in the case of the dihydropyridine, this could be overcome by mixing the product mixture with a stream of ethyl acetate via a T-piece as soon as it comes out of the heated zone.

Table 2. Probing the energy efficiency of the microwave-promoted Suzuki coupling reaction<smiles>COc1ccc(-c2ccccc2)cc1</smiles>

\begin{tabular}{|c|c|c|c|c|c|}
\hline Entry & Conditions & $\begin{array}{l}\text { Reaction time } \\
(\min )^{\mathrm{a}}\end{array}$ & Yield (\%) & $\begin{array}{c}\text { energy used } \\
(\mathrm{Wh})^{\mathrm{b}}\end{array}$ & $\begin{array}{c}\text { Wh. } \\
\text { mmol- }^{1}\end{array}$ \\
\hline 1 & $\begin{array}{l}1 \text { mmol sealed vessel }{ }^{\mathrm{C}} \\
(\text { initial MW power } 50 \mathrm{~W} \text { ) }\end{array}$ & 3 & 93 & 9.1 & 9.8 \\
\hline 2 & $\begin{array}{l}1 \text { mmol sealed vessel } \\
\text { (initial MW power } 200 \mathrm{~W} \text { ) }^{\mathrm{C}}\end{array}$ & 3 & 88 & 9.5 & 10.8 \\
\hline 3 & $\begin{array}{l}1 \mathrm{mmol} \text { sealed vessel }{ }^{\mathrm{c}} \\
\text { (initial MW power } 300 \mathrm{~W} \text { ) }\end{array}$ & 3 & 87 & 9.1 & 10.5 \\
\hline 4 & $10 \mathrm{mmol} \mathrm{sealed} \mathrm{vessel}^{\mathrm{c}}$ & 10 & 97 & 46.1 & 4.8 \\
\hline 5 & $10 \mathrm{mmol}$ open vessel ${ }^{\mathrm{c}}$ & 10 & 73 & 33.6 & 4.5 \\
\hline 6 & 20 mmol open vessel ${ }^{\mathrm{c}}$ & 10 & 90.3 & 35.8 & 2.0 \\
\hline 7 & 100 mmol open vessel $^{\mathrm{d}}$ & 20 & 98 & 250 & 2.6 \\
\hline 8 & 200 mol open vessel $^{\mathrm{d}}$ & 20 & 76 & 260 & 1.7 \\
\hline 9 & 200 mmol sealed vessel $^{\mathrm{d}}$ & 20 & 79 & 300 & 2.0 \\
\hline 10 & $50 \mathrm{mmol} \mathrm{flow}^{\mathrm{e}}$ & 5 & 84 & 175.2 & 4.2 \\
\hline 11 & $100 \mathrm{mmol}^{\text {flow }^{\mathrm{e}}}$ & 5 & 89 & 266 & 3.0 \\
\hline
\end{tabular}

${ }^{a}$ total reaction time.

benergy consumption as measured by the power meter for the entire reaction time.

c performed in a monomode microwave unit.

performed in a multimode microwave unit.

e performed using conventional heating in continuous-flow mode. 
To perform the study, the heating block was first heated from room temperature to the target temperature of $140{ }^{\circ} \mathrm{C}$, passing ethanol / water through the coil reactor, from bottom to top, at a rate of $2.8 \mathrm{ml} / \mathrm{min}$, this taking $79 \mathrm{Wh}$ of energy. Once at temperature, the flow was then changed from solvent to reaction mixture. A $50 \mathrm{mmol}$ batch of reaction mixture was then passed through the coil reactor. As in the case of the dihydropyridine synthesis, after all the reaction mixture has entered the coil reactor, the flow was changed back to solvent to push the remaining reaction mixture through and out into the collection vessel. The total energy used was noted as 175.2 Wh. The entire process was repeated but on the $100 \mathrm{mmol} \mathrm{scale}$, this requiring $266 \mathrm{Wh}(80$ Wh for heating to temperature and $186 \mathrm{Wh}$ to process the reaction mixture). Factoring in the

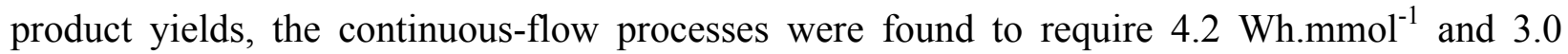
Wh.mmol ${ }^{-1}$ for $50 \mathrm{mmol}$ and $100 \mathrm{mmol}$ scales respectively (Table 2, entries 10 and 11). The result at the $100 \mathrm{mmol}$ level is comparable to that obtained using microwave heating at the same scale. This is different to the case of the dihydropyridine synthesis where, on the $100 \mathrm{mmol}$ scale, microwave heating was markedly more energy efficient than the conventionally heated flow approach. However, in the Suzuki coupling protocol, the reaction mixture is in the heated zone for only $5 \mathrm{~min}$, meaning that the total volume is processed in a third of the time. Even though a higher temperature was required $\left(140{ }^{\circ} \mathrm{C}\right.$ for the Suzuki coupling vs $110{ }^{\circ} \mathrm{C}$ in the dihydropyridine synthesis) and a faster flow rate was used (i.e. a greater energy requirement was made of the pumping mechanism) this rapid processing meant that the energy consumption per mmol of product formed was significantly less. This indicates that conventionally heated flow chemistry becomes increasingly more energy efficient as the scale and the flow rate increases.

\section{Preparation of $N$-phenylpiperidine}

The double alkylation of anilines using dihaloalkanes has been reported to occur in mildly basic aqueous media upon microwave irradiation to afford a series of $N$-aryl azacycloalkanes. ${ }^{12}$ The reaction is complete within $20 \mathrm{~min}$ at $120^{\circ} \mathrm{C}$ in a sealed tube and has also been scaled up using an open vessel approach. ${ }^{13}$ Given this literature precedent we decided to study the reaction from the perspective of energy consumption using both microwave and conventional batch heating. We started our work on the $20 \mathrm{mmol}$ scale, performing the reaction both in a sealed tube and an open vessel using microwave heating and recording energy consumptions of $4.3 \mathrm{Wh} . \mathrm{mmol}^{-1}$ and 7.7 Wh.mmol ${ }^{-1}$ respectively (Table 3, entries 1 and 2). Although there was a significant difference in values when normalized to $\mathrm{Wh}_{\mathrm{mmol}}{ }^{-1}$, the main difference between the two is not the energy consumed ( $71.8 \mathrm{wh}$ for sealed vessel processing and $82.6 \mathrm{wh}$ for open vessel) but the product yield obtained ( $83 \%$ for sealed vessel processing and $54 \%$ for open vessel).

We moved next to the $200 \mathrm{mmol}$ scale, performed the reaction initially using an open vessel approach at reflux temperature and determined an energy consumption of $2.39 \mathrm{Wh} . \mathrm{mmol}^{-1}$ (Table 3, entry 3). While this shows that the energy consumption decreases as scale increases, we noticed that as we scaled directly from the $20 \mathrm{mmol}$ to the $200 \mathrm{mmol}$ scale, the volume of water used in the reaction became quite considerable and that the organic substrates are simply suspended in the mixture. It occurred to us that it may be possible to reduce the volume of water 
used without a deleterious effect on the product yield. Thus, we re-ran the reaction using only half the volume of water. We obtained a better yield of the desired product (78\% vs. 67\%) and, not unexpectedly, the energy consumption dropped (1.92 Wh.mmol ${ }^{-1}$; Table 3 , entry 4) since the reaction volume was substantially lower and thus the microwave energy required for heating to and holding at reflux was reduced. We next performed the reaction in a sealed vessel at $120{ }^{\circ} \mathrm{C}$, again using a reduced volume of water. We recorded an energy consumption of $1.20 \mathrm{Wh} . \mathrm{mmol}^{-1}$ (Table 3, entry 5), similar to the open vessel analog.

Table 3. Probing the energy efficiency of the microwave-promoted synthesis of $N$ phenylpiperidine

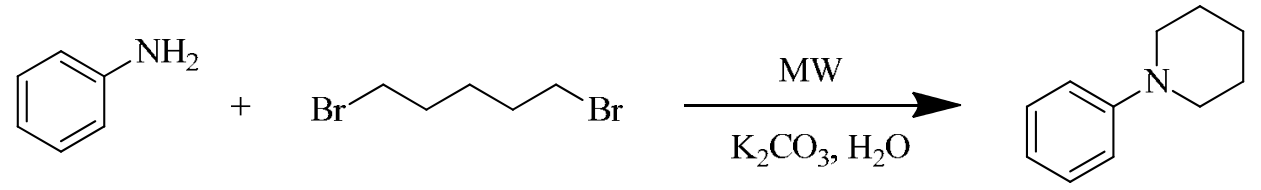

\begin{tabular}{|c|c|c|c|c|c|}
\hline Entry & Conditions & $\begin{array}{l}\text { Reaction time } \\
\qquad(\min )^{\mathrm{a}}\end{array}$ & $\begin{array}{l}\text { Yield } \\
(\%)\end{array}$ & $\begin{array}{c}\text { Energy used } \\
(\mathrm{Wh})^{\mathrm{b}}\end{array}$ & $\underset{1}{\text { Wh.mmol }}$ \\
\hline 1 & $20 \mathrm{mmol}^{\mathrm{mealed}} \mathrm{vessel}^{\mathrm{c}}$ & 20 & 83 & 71.8 & 4.3 \\
\hline 2 & $20 \mathrm{mmol}$ open vessel ${ }^{\mathrm{c}}$ & 20 & 54 & 82.6 & 7.7 \\
\hline 3 & 200 mmol open vessel $^{\mathrm{d}}$ & 20 & 67 & 320.1 & 2.39 \\
\hline 4 & $\begin{array}{c}200 \text { mmol open } \\
\text { vessel }^{\mathrm{d}, \mathrm{e}}\end{array}$ & 20 & 78 & 300.2 & 1.92 \\
\hline 5 & $\begin{array}{c}200 \mathrm{mmol}_{\text {sealed }} \\
\text { vessel }^{\mathrm{d}, \mathrm{e}}\end{array}$ & 20 & 92 & 220.1 & 1.20 \\
\hline 6 & $\begin{array}{c}500 \text { mmol open } \\
\text { vessel }^{\text {d,f }}\end{array}$ & 20 & 76 & 350.3 & 0.92 \\
\hline 7 & $\begin{array}{c}500 \text { mmol open } \\
\text { vessel }^{\mathrm{f}, \mathrm{g}} \\
\text { (conventional heating) }\end{array}$ & 35 & 91 & 274.5 & 0.61 \\
\hline
\end{tabular}

atotal reaction time.

benergy consumption as measured by the power meter for the entire reaction time.

c performed in a monomode microwave unit.

d performed in a multimode microwave unit.

e performed using only half the volume of water as that in entry 3.

performed at the same concentration as that in entry 5 .

${ }^{\mathrm{g}}$ performed using a snug-fitting heating mantle. 
Finally we moved to the 0.5 mole scale and ran the reaction in an open vessel at reflux, initially using microwave heating. We recorded an energy consumption of 0.92 Wh.mmol ${ }^{-1}$ (Table 3, entry 6). We decided to compare this with a conventionally heated batch analog. To undertake this, we used the same vessel and the same volume of reaction mixture but performed the reaction using a heating mantle. We envisaged that the heat-up stage would be substantially longer than in the case of microwave irradiation. In an attempt to equate the two heating methods, we revisited our microwave process to determine what for length of the 20 min heating period the reaction mixture was at reflux. We determined it to be $17 \mathrm{~min}$ and thus, in the case of the conventionally heated reaction, we decided to heat to reflux and hold for $17 \mathrm{~min}$. Performing this experiment we found the total time from start to finish was $35 \mathrm{~min}$, during which the energy consumed was $0.61 \mathrm{Wh}^{\mathrm{mmol}}{ }^{-1}$ (Table 3, entry 7) This is a little lower than the trial using microwave heating but the difference was not substantial.

\section{Comparison of microwave and conventional heating in batch mode}

To probe further the energy efficiency of a heating mantle and multimode microwave unit, we performed a series of simple experiments involving heating $1 \mathrm{~L}$ of water from room temperature to its boiling point (results shown pictorially in Figure 1). Since the specific heat capacity of water is known $\left(4.18 \mathrm{J.g}^{-1} \mathrm{~K}^{-1}\right)$ and $1 \mathrm{~W}=1 \mathrm{Js}^{-1}$, we could determine the efficiency of the process using eq. 1 .

$$
\text { efficiency }=\frac{4.18 \times 1000 \times \Delta T}{\text { Wh consumed } \times 3600}
$$

For conventional heating, to raise $1 \mathrm{~L}$ water from $27^{\circ} \mathrm{C}$ to $100^{\circ} \mathrm{C}$ took $22 \mathrm{~min}$ and consumed $184 \mathrm{Wh}$; this makes the process $46 \%$ efficient overall. Performing similar calculations for the microwave heated example show it to be $44 \%$ efficient overall (heating $1 \mathrm{~L}$ water from $27^{\circ} \mathrm{C}$ to $100{ }^{\circ} \mathrm{C}$ took $4.66 \mathrm{~min}$ and consumed $190 \mathrm{Wh}$ ). Thus, there is little difference in overall efficiency between the two heating methods. We looked next at the efficiency of the magnetron in the microwave unit. It was operating at a microwave power of $1600 \mathrm{~W}$ but was drawing 2600 $\mathrm{W}$ from the electrical circuit. This makes the magnetron $62 \%$ efficient. When using conventional heating the heating mantle was drawing $488 \mathrm{~W}$ from the electrical circuit. If the process were $100 \%$ efficient in turning electrical energy into heat this would correspond to $179 \mathrm{Wh}$ consumed during the $22 \mathrm{~min}$ heating process $(488 \mathrm{~W} \times 0.36 \mathrm{~h})$. The measured energy consumption of 184 Wh means that the heating mantle is $97 \%$ efficient in turning electrical energy into heat.

Bringing these data together, although the conversion of electrical energy into heat by the heating mantle is significantly more efficient than conversion of electrical energy into microwave energy by the magnetron of the microwave unit, the fact that the water can be heated 
to its boiling point so much faster using microwave irradiation as opposed to conventional heating means that, overall, the two methods are comparable in their energy consumption.

\section{conventional heating}

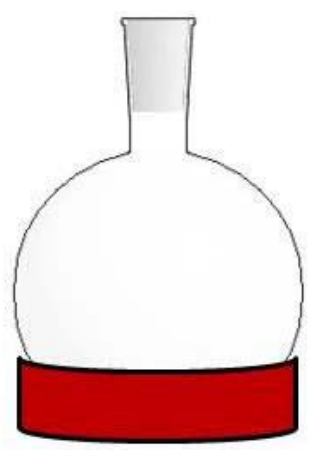

22 min to heat $1 \mathrm{~L}$ of water from r.t. to $100{ }^{\circ} \mathrm{C}$

187 Wh comsumed

$97 \%$ efficient in turning electrical energy to heat overall efficiency $=46 \%$

\section{microwave heating}

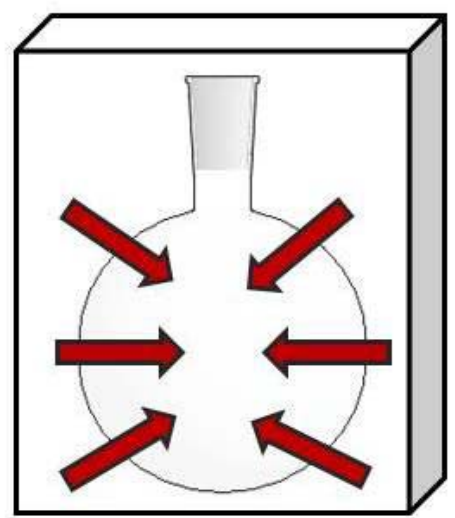

4.67 min to heat $1 \mathrm{~L}$ of water from r.t. to $100{ }^{\circ} \mathrm{C}$ 190 Wh consumed magnetron is $66 \%$ efficient overall efficiency $=44 \%$

Figure 1. Energy comparisons between microwave and conventional heating of $1 \mathrm{~L}$ of water from room temperature to its boiling point.

\section{Conclusions}

We have probed the energy efficiency of using microwave heating in three reactions and, in two cases, compared the data with that obtained using a conventionally heated flow approach. We find that, in each reaction, as the scale is increased so the energy efficiency improves. In addition, the energy consumption is similar for both sealed and open vessel microwave processing. When using a conventionally-heated flow approach, performing reactions on large scales and passing the material through the heated zone rapidly offer the best operating parameters from an energy standpoint. In one case we have compared conventional and microwave heating in batch mode and find that the conventionally heated reaction is a little more energy efficient compared to the case of microwave heating but the difference was not substantial. To probe the differences between conventional and microwave batch heating further we have performed some calculations based on heating water from room temperature to its boiling point. We find that while the conversion of electrical energy into heat by a heating mantle is significantly more efficient than conversion of electrical energy into microwave energy by the magnetron of a microwave unit, the fact that the water can be heated to its boiling point so 
much faster using microwave irradiation as opposed to conventional heating means that, overall, the two methods are comparable in their energy consumption. These results in addition to the ease of use, safety and rapid heating possible make microwave and continuous-flow conventional heating attractive tools for synthetic chemistry as compared to conventional batch methods at least on scales up to the mole level.

\section{Experimental Section}

General. All reagents were obtained from commercial suppliers and used without further purification. ${ }^{1} \mathrm{H}$ NMR spectra were recorded at $293 \mathrm{~K}$ on a 300 or $400 \mathrm{MHz}$ spectrometer.

Equipment used. Microwave reactions were performed using a CEM Discover unit (operating at $110 \mathrm{~V}$, microwave irradiation of $2.45 \mathrm{GHz}$, maximum microwave output of $300 \mathrm{~W}$ ) in either $10 \mathrm{~mL}$ or $80 \mathrm{~mL}$ capacity sealed tubes or $100 \mathrm{~mL}$ capacity open round-bottom flasks or using a CEM MARS Synthesis unit (operating at $208 \mathrm{~V}$, microwave irradiation of $2.45 \mathrm{GHz}$, maximum microwave output of $1600 \mathrm{~W}$ ) using round-bottom flasks ranging from $1 \mathrm{~L}$ to $3 \mathrm{~L}$ or a $1 \mathrm{~L}$ capacity Teflon sealed vessel. ${ }^{19}$ For experiments performed using a conventionally-heated continuous-flow approach, a Uniqsis FlowSyn unit was used. ${ }^{16}$ For experiments performed using conventional batch heating a heating mantle capable of containing a 3 L round-bottom flask was used. A magnetic stir-plate was positioned below the heating mantle to allow for stirring of the reaction mixture. Power measurement was achieved using either a "Watts Up Pro" or a "Plug-in Power \& Energy Monitor" meter set in series between the wall power socket and the microwave unit, flow unit or heating mantle.

\section{General experimental procedures for the reactions performed in this study}

Four representative procedures are given for the synthesis of the 1,4-dihydropyridine using microwave heating, followed by one selected procedure for the other two reactions and then a procedure for the conventionally heated analogs (flow and batch).

\section{Synthesis of the 1,4-dihydropyridine in a sealed vessel using the Discover microwave unit} Benzaldehyde (1.06 g, $10 \mathrm{mmol})$, ethyl acetoacetate $(4.3 \mathrm{~mL}, 32 \mathrm{mmol})$, concentrated ammonium hydroxide $(5.6 \mathrm{~mL}, 161 \mathrm{mmol})$, ethanol $(10 \mathrm{~mL})$, and water $(10 \mathrm{~mL})$ were combined in an $80 \mathrm{~mL}$ thick walled glass vessel equipped with a magnetic stir bar. The vessel was sealed and placed into the microwave cavity. A Watts Up Pro wattage meter was connected in series between the microwave unit and the wall power socket. The reaction mixture was heated to 110 ${ }^{\circ} \mathrm{C}$ using an initial microwave power of $50 \mathrm{~W}$ and held at this temperature until a total reaction time of $15 \mathrm{~min}$ had elapsed. The contents of the vessel were then cooled to $50{ }^{\circ} \mathrm{C}$ using compressed air. The power consumption was measured from the start of the run until the cooling commenced. The crude product mixture was placed into a separatory funnel. Water $(25 \mathrm{~mL})$ and 
ethyl acetate $(25 \mathrm{~mL})$ were added and the organic material extracted and removed. After further extraction of the aqueous layer with ethyl acetate (total of $3 \times 25 \mathrm{~mL}$ ) the organics were combined, washed with brine $(10 \mathrm{~mL})$ and then dried over $\mathrm{MgSO}_{4}$. The ethyl acetate was removed in vacuo leaving the crude product, which was characterized as 2,6-dimethyl-4-phenyl1,4-dihydro-pyridine-3,5-dicarboxylic acid diethyl ester by comparison of NMR data with that in the literature. ${ }^{15}$ The yield was determined as $(7.10 \mathrm{mmol}, 71 \%$ yield $)$ by use of $1,2,4,5-$ tetramethylbenzene as an internal standard. ${ }^{1} \mathrm{H}$ NMR $\left(300 \mathrm{MHz}, \mathrm{CDCl}_{3}\right) \delta=7.28(\mathrm{~d}, J=10.7$ $\mathrm{Hz}, 2 \mathrm{H}), 7.20$ (t, $J=7.5 \mathrm{~Hz}, 2 \mathrm{H}), 7.12(\mathrm{t}, J=7.3 \mathrm{~Hz}, 2 \mathrm{H}), 5.59$ (bs, 1H), 4.99 (s, 1H), 4.08 (m, $4 \mathrm{H}), 2.33(\mathrm{~s}, 6 \mathrm{H}), 1.22(\mathrm{t}, J=7.1 \mathrm{~Hz}, 6 \mathrm{H})$.

\section{Synthesis of the 1,4-dihydropyridine in an open vessel using the Discover microwave unit} Benzaldehyde $(1.06 \mathrm{~g}, 10 \mathrm{mmol})$, ethyl acetoacetate $(4.3 \mathrm{~mL}, 32 \mathrm{mmol})$, concentrated ammonium hydroxide $(5.6 \mathrm{~mL}, 161 \mathrm{mmol})$, ethanol $(10 \mathrm{~mL})$, and water $(10 \mathrm{~mL})$ were combined in a $100 \mathrm{~mL}$ round-bottom flask equipped with a magnetic stir bar. The flask was placed in the cavity of a CEM Discover microwave unit, an attenuator locked in position and a reflux condenser seated on the flask. A Watts Up Pro wattage meter was connected in series between the microwave unit and the wall power socket. The reaction mixture was heated to reflux using an initial microwave power of $50 \mathrm{~W}$ and then the power reduced to hold the reaction mixture at a steady reflux until a total reaction time of $15 \mathrm{~min}$ had elapsed. The contents of the vessel were then cooled to $50{ }^{\circ} \mathrm{C}$ using compressed air. The power consumption was measured from the start of the run until the cooling commenced. The product was isolated, characterized and the yield determined in a manner identical to that for the sealed vessel experiment.

\section{Synthesis of the 1,4-dihydropyridine in an open vessel using the MARS microwave unit} Benzaldehyde (10.6 g, $100 \mathrm{mmol})$, ethyl acetoacetate $(43 \mathrm{~mL}, 320 \mathrm{mmol})$, concentrated ammonium hydroxide $(56 \mathrm{~mL}, 1.61 \mathrm{~mol})$, ethanol $(100 \mathrm{~mL})$, and water $(100 \mathrm{~mL})$ were combined in a $1 \mathrm{~L}$ two-neck round bottom flask equipped with a magnetic stir bar. The flask was placed in the cavity of a CEM MARS microwave unit with a fiber optic probe lowered in to the reaction mixture through a thermal well inserted into a septum in one of the vessel necks. A reflux condenser was placed in the other neck of the flask. A Plug-in Power \& Energy Monitor wattage meter was connected in series between the microwave unit and the wall power socket. The reaction mixture was heated to reflux using an initial microwave power of $1600 \mathrm{~W}$ and then the power reduced to hold the reaction mixture at a steady reflux until a total reaction time of $15 \mathrm{~min}$ had elapsed. The contents of the vessel were then cooled to $50{ }^{\circ} \mathrm{C}$. The power consumption was measured from the start of the run until the cooling commenced. The product was isolated, characterized and the yield determined in a manner identical to that for the smaller-scale experiments.

Synthesis of the 1,4-dihydropyridine in a sealed vessel using the MARS microwave unit Benzaldehyde (10.6 g, $100 \mathrm{mmol})$, ethyl acetoacetate (43 mL, $320 \mathrm{mmol})$, concentrated 
ammonium hydroxide (56 mL, $1.61 \mathrm{~mol})$, ethanol $(100 \mathrm{~mL})$, and water $(100 \mathrm{~mL})$ were combined in a $1 \mathrm{~L}$ Teflon vessel with a magnetic stir bar. The vessel was sealed, a fiber-optic probe inserted into a thermal well located in the top of the vessel cover and the vessel assembly placed in the cavity of a CEM MARS microwave unit. The wattage meter was connected and the reaction mixture was heated to $110^{\circ} \mathrm{C}$ using an initial microwave power of $1600 \mathrm{~W}$ and then the power reduced to hold the reaction mixture at a steady reflux until a total reaction time of $15 \mathrm{~min}$ had elapsed. The contents of the vessel were then cooled to $50^{\circ} \mathrm{C}$. The power consumption was measured from the start of the run until the cooling commenced. The product was isolated, characterized and the yield determined in a manner identical to that for the smaller-scale experiments.

\section{Suzuki coupling of 4-bromoanisole and phenylboronic acid in a sealed vessel using the Discover microwave unit}

4-Bromoanisole (1.87 g, $10 \mathrm{mmol})$, phenylboronic acid (1.46 g, $12 \mathrm{mmol})$, sodium carbonate $(3.92 \mathrm{~g}, 37 \mathrm{mmol})$, ethanol $(10 \mathrm{~mL})$, and an aliquot of palladium ICP standard solution (5 ppm, $10 \mathrm{~mL}$ ) were combined in an $80 \mathrm{~mL}$ thick walled glass vessel equipped with a magnetic stir bar. The wattage meter was connected and the reaction mixture was heated to $150{ }^{\circ} \mathrm{C}$ using an initial microwave power of $50 \mathrm{~W}$ and held at this temperature until a total reaction time of $10 \mathrm{~min}$ had elapsed. The contents of the vessel were then cooled to $50{ }^{\circ} \mathrm{C}$ using compressed air. The power consumption was measured from the start of the run until the cooling commenced. The crude product mixture was placed into a separatory funnel. Water $(25 \mathrm{~mL})$ and diethyl ether $(20 \mathrm{~mL})$ were added and the organic material extracted and removed. After further extraction of the aqueous layer with diethyl ether (total of $3 \times 20 \mathrm{~mL}$ ) the organics were combined, washed with water $(30 \mathrm{~mL})$ then brine $(30 \mathrm{~mL})$ and then dried over $\mathrm{MgSO}_{4}$. The diethyl ether was removed in vacuo leaving the crude product, which was characterized as 4-methoxybiphenyl by comparison of NMR data with that in the literature. ${ }^{18}$ The yield was determined as $(9.68 \mathrm{mmol}, 97 \%$ yield $)$ by use of 1,2,4,5-tetramethylbenzene as an internal standard. ${ }^{1} \mathrm{H}$ NMR $\left(300 \mathrm{MHz}, \mathrm{CDCl}_{3}\right) \delta=$ $7.54(\mathrm{~m}, 2 \mathrm{H}), 7.52,6.97\left(\mathrm{AA}^{\prime} X X^{\prime}\right.$ peak, $\left.J_{a a^{\prime}}=J_{x x^{\prime}}=1.9, J_{a x} 7.8, J_{a x^{\prime}} 0.6 \mathrm{~Hz}, 4 \mathrm{H}\right), 7.40(\mathrm{~m}, 2 \mathrm{H})$, $7.28(\mathrm{~m}, 1 \mathrm{H}), 3.84(\mathrm{~s}, 3 \mathrm{H})$.

Preparation of $\mathbf{N}$-phenylpiperidine in an open vessel using the MARS microwave unit Aniline (18.6 g, $200 \mathrm{mmol})$, 1,5-dibromopentane $(50.6 \mathrm{~g}, 220 \mathrm{mmol})$, potassium carbonate (30.4 g, $220 \mathrm{mmol})$, and water $(200 \mathrm{~mL})$ were combined in a $1 \mathrm{~L}$ two-neck round bottom flask equipped with a magnetic stir bar. The flask was placed in the cavity of a CEM MARS microwave unit with a fiber optic probe lowered in to the reaction mixture through a thermal well inserted into a septum in one of the vessel necks. A reflux condenser was placed in the other neck of the flask. The wattage meter was connected and the reaction mixture was heated to reflux using an initial microwave power of $1600 \mathrm{~W}$ and then the power reduced to hold the reaction mixture at a steady reflux until a total reaction time of $20 \mathrm{~min}$ had elapsed. The contents of the vessel were then cooled to $50^{\circ} \mathrm{C}$. The crude product mixture was placed into a separatory 
funnel. Water $(100 \mathrm{~mL})$ and ethyl acetate $(100 \mathrm{~mL})$ were added and the organic material extracted and removed. After further extraction of the aqueous layer with ethyl acetate (total of 3 $\times 100 \mathrm{~mL})$ the organics were combined, washed with water $(100 \mathrm{~mL})$ then brine $(100 \mathrm{~mL})$ and then dried over $\mathrm{MgSO}_{4}$. The ethyl acetate was removed in vacuo leaving the crude product, which was characterized as $N$-phenylpiperidine by comparison of NMR data with that in the literature. $^{20}$ The yield was determined as (156 mmol, 78\% yield) by NMR using 1,2,4,5tetramethylbenzene as an internal standard. ${ }^{1} \mathrm{H}$ NMR $\left(300 \mathrm{MHz}, \mathrm{CDCl}_{3}\right) \delta=7.27(\mathrm{t}, 2 \mathrm{H}, J=7.4$ $\mathrm{Hz}), 6.89$ (d, 2H, $J=7.8 \mathrm{~Hz}), 6.75(\mathrm{t}, 1 \mathrm{H}, J=7.3 \mathrm{~Hz}), 3.13$ (t, 4H, $J=6.7 \mathrm{~Hz}), 1.62(\mathrm{~m}, 4 \mathrm{H})$, $1.45(\mathrm{t}, 2 \mathrm{H}, J=4.8 \mathrm{~Hz})$

\section{Synthesis of the 1,4-dihydropyridine using a conventionally heated continuous-flow approach}

Benzaldehyde (10.6 g, $100 \mathrm{mmol})$, ethyl acetoacetate $(43 \mathrm{~mL}, 320 \mathrm{mmol})$, concentrated ammonium hydroxide $(56 \mathrm{~mL}, 1.61 \mathrm{~mol})$, ethanol $(100 \mathrm{~mL})$, and water $(100 \mathrm{~mL})$ were combined in a $500 \mathrm{~mL}$ glass bottle equipped with a top that allows tube access. A $14 \mathrm{~mL}$ capacity PTFE coil reactor was put in place around the aluminium heating block of the FlowSyn. At the exit of the coil reactor, a T-piece mixer was placed and this linked to a second input line which, in turn, was placed into a $250 \mathrm{~mL}$ bottle containing ethyl acetate. A short length of PTFE tubing was placed between the T-piece and a 100 psi rated back-pressure regulator. A small length of PTFE tubing was attached to the exit of the back-pressure regulator, this being used to take product mixture to a $100 \mathrm{~mL}$ capacity collection vessel via a heat-exchanger unit. The wattage meter was connected and the block was heated from room temperature to $110{ }^{\circ} \mathrm{C}$, passing ethanol / water (1:1 mixture) through the coil reactor, from bottom to top, at a rate of $1 \mathrm{~mL} / \mathrm{min}$. The flow was then changed from solvent to reaction mixture by means of a switch on the control unit. The reaction mixture was then passed through the coil reactor at a rate of $1 \mathrm{~mL} / \mathrm{min}$. As the mixture neared the end of the coil reactor, an empty, clean collection vessel was put in place and a flow of ethyl acetate $(5 \mathrm{~mL} / \mathrm{min})$ started into the T-piece mixer. After all the reaction mixture has entered the coil reactor, the flow was changed back to solvent and this flowed through the reactor at a rate of $1 \mathrm{~mL} / \mathrm{min}$ to push the remaining reaction mixture through and out into the collection vessel. As soon as this was achieved, the flow was stopped and the energy reading recorded. The product was isolated, characterized and the yield determined in a manner identical to that for the trials using microwave heating.

\section{Suzuki coupling of 4-bromoanisole and phenylboronic acid using a conventionally heated continuous-flow approach}

4-Bromoanisole (18.7 g, $100 \mathrm{mmol}$ ), phenylboronic acid (14.6 g, $120 \mathrm{mmol}), \mathrm{NaOH}$ (8 g, 200 $\mathrm{mmol})$, ethanol $(100 \mathrm{~mL})$, water $(100 \mathrm{~mL})$ and an aliquot of palladium ICP standard solution $(1000 \mathrm{ppm}, 160 \mu \mathrm{L})$ were combined in a $500 \mathrm{~mL}$ glass bottle equipped with a top that allows tube access. The FlowSyn was set up in a manner identical to that for the case of the 1,4dihydropyridine synthesis. The wattage meter was connected and the block was heated from 
room temperature to $140{ }^{\circ} \mathrm{C}$, passing ethanol / water (1:1 mixture) through the coil reactor, from bottom to top, at a rate of $2.8 \mathrm{ml} / \mathrm{mL}$. The flow was then changed from solvent to reaction mixture by means of a switch on the control unit. The reaction mixture was then passed through the coil reactor at a rate of $2.8 \mathrm{~mL} / \mathrm{min}$. As the mixture neared the end of the coil reactor, an empty, clean collection vessel was put in place and a flow of ethyl acetate $(5 \mathrm{~mL} / \mathrm{min})$ started into the T-piece mixer. After all the reaction mixture has entered the coil reactor, the flow was changed back to solvent and this flowed through the reactor at a rate of $2.8 \mathrm{~mL} / \mathrm{min}$ to push the remaining reaction mixture through and out into the collection vessel. As soon as this was achieved, the flow was stopped and the energy reading recorded. The product was isolated, characterized and the yield determined in a manner identical to that for the trials using microwave heating.

\section{Preparation of $\boldsymbol{N}$-phenylpiperidine in an open vessel using a heating mantle}

Aniline (18.6 g, $200 \mathrm{mmol})$, 1,5-dibromopentane (50.6 g, $220 \mathrm{mmol})$, potassium carbonate (30.4 $\mathrm{g}, 220 \mathrm{mmol})$, and water $(200 \mathrm{~mL})$ were combined in a $1 \mathrm{~L}$ one-neck round bottom flask equipped with a magnetic stir bar. The flask was placed into the heating mantle which in turn was located on top of a magnetic stirrer plate. A reflux condenser was placed in the neck of the flask. The wattage meter was connected and the reaction mixture was heated to reflux using fullpower and then the power reduced to hold the reaction mixture at a steady reflux until a total reaction time of $35 \mathrm{~min}$ had elapsed. The contents of the vessel were then cooled to $50{ }^{\circ} \mathrm{C}$. The power consumption was measured from the start of the run until the cooling commenced. The product was isolated, characterized and the yield determined in a manner identical to that for the microwave heating experiment.

\section{Acknowledgements}

We thank the American Chemical Society Petroleum Research Foundation (45433-AC1) and the National Science Foundation (CAREER award CHE-0847262) for funding. CEM Corp. are thanked for microwave equipment support and Uniqsis Inc. for access to a FlowSyn continuousflow unit.

\section{References}

1. For a recent overview of the field see: Loupy, A. Ed. Microwaves in Organic Synthesis, Wiley: Weinheim, 2006.

2. For a discussion of scale-up of microwave-assisted organic synthesis see: Moseley, J. D. In Leadbeater, N. E. Ed., Microwave Heating as a Tool for Sustainable Chemistry, Taylor and Francis: Boca Raton FL, 2010. 
3. For reviews see: (a) Lehmann, H. In New Avenues to Efficient Chemical Synthesis, Seeberger, P.H.; Blume, T. Eds., Springer-Verlag: Berlin, 2007. (b) Roberts B. A.; Strauss, C. R. Acc. Chem. Res. 2005, 38, 653.

4. Gronnow, M. J.; White, R. J.; Clark, J. H.; Macquarrie, D. J. Org. Proc. Res. Dev. 2005, 9, 516 [corrigendum: Gronnow, M. J.; White, R. J. Clark, J. H.; Macquarrie, D. J. Org. Proc. Res. Dev. 2007, 11, 293].

5. Razzaq, M.; Kappe, C. O. Chem. Sus. Chem. 2008, 1, 123.

6. Nüchter, M.; Müller, U.; Ondruschka, B.; Tied, A.; Lautenschläger, W. Chem. Eng. Technol. 2003, 26, 1207.

7. Hoogenboom, R.; Wilms, T. F. A.; Erdmenger, T.; Schubert, U. S. Aust. J. Chem. 2009, 62, 236.

8. Moseley, J. D.; Woodman, E. K. Energy Fuels 2009, 23, 5438.

9. Komorowska, M.; Stefanidis, G. D.; Van Gerven, T.; Stankiewicz, A. I. Chem. Eng. J. 2009, $155,859$.

10. Dressen, M. H. C. L.; van de Kruijs, B. H. P.; Meuldijk, J.; Vekemans, J. A. J. M.; Hulshof, L. A. Org. Proc. Res. Dev. 2010, 14, 351.

11. Damm, M.; Glasnov, T. N.; Kappe, C. O. Org. Proc. Res. Dev. 2010, 14, 215.

12. (a) Ju, Y.; Varma, R. S. J. Org. Chem. 2006, 71, 135 (b) Ju, Y.; Varma, R. S. Org. Lett. 2005, 7, 2409.

13. Barnard T. M.; Vanier, G.; Collins M. J. Org. Proc. Res. Dev., 2006, 10, 1233.

14. For a review see: Vanden Eynde, J. J. Mayence, A. Molecules 2003, 8, 381.

15. Bowman, M. D.; Holcomb, J. L.; Kormos, C. M.; Leadbeater, N. E.; Williams, V. A. Org. Proc. Res. Dev. 2008, 12, 41.

16. www.uniqsis.com

17. For a review of the Suzuki reaction using water as a solvent in conjunction with microwave heating see: Leadbeater, N. E. Chem. Commun. 2005, 2881.

18. (a) Schmink, J.R.; Kormos, C.M.; Devine, W.G.; Leadbeater, N.E. Org. Proc. Res. Dev. 2010, 14, 205. (b) Bowman, M. D.; Schmink, J. R.; McGowan, C. M.; Kormos, C. M.; Leadbeater, N. E. Org. Proc. Res. Dev. 2008, 12, 1078. (c) Leadbeater, N. E.; Williams, V. A.; Barnard T. M.; Collins M. J. Org. Proc. Res. Dev. 2006, 10, 833. (d) Arvela, R. K.; Leadbeater, N. E.; Collins, M. J. Tetrahedron 2005, 61, 9349. (e) Arvela, R. K.; Leadbeater, N. E. Org. Lett. 2005, 7, 2101. (f) Arvela, R. K.; Leadbeater, N. E.; Sangi, M. S.; Williams, V. A.; Granados, P.; Singer, R. D., J. Org. Chem. 2005, 70, 1786.

19. www.cem.com

20. Ju, Y.; Varma, R. S Org. Lett., 2005, 7, 2409. 